\title{
Efeito da Temperatura Ambiente e da Restrição Alimentar sobre o Desempenho e a Composição da Carcaça de Frangos de Corte $^{1}$
}

\author{
Geraldo Roberto Quintão Lana ${ }^{2}$, Horacio Santiago Rostagno ${ }^{3}$, Luiz Fernando Teixeira Albino ${ }^{3}$, \\ Ângela Maria Quintão Lana ${ }^{4}$
}

\begin{abstract}
RESUMO - O objetivo deste experimento foi estudar os efeitos da temperatura ambiente e da restrição alimentar sobre o desempenho produtivo, o rendimento das carcaças e dos cortes nobres e os teores de gordura, água e proteína das carcaças e os teores de glicogênio do fígado de frangos de corte em diferentes condições ambientais. O delineamento experimental usado foi em blocos casualizados, em esquema fatorial 5 x 2 (programa alimentar e sexo) com duas repetições dentro de cada ambiente e 14 aves por unidade experimental. Aos 42 dias de idade, o consumo de ração e o ganho de peso foram influenciados negativamente pela temperatura e pelo sexo, porém não foram afetados pelo programa de restrição alimentar. Os rendimentos de carcaça e de cortes nobres não foram influenciados pela temperatura, pelos programas de restrição alimentar e pelo sexo. Os programas de restrição alimentar e a temperatura não influenciaram os teores de gordura, água e proteína da carcaça. As fêmeas apresentaram maior teor de gordura nas carcaças. Já os teores de glicogênio do fígado foram negativamente influenciados pelos programas de restrição alimentares e pelo sexo, porém não foram afetados pela temperatura.
\end{abstract}

Palavras-chave: frangos de corte, gordura abdominal, gordura total, programa alimentar, rendimentos de carcaça e cortes nobres, sexo, temperatura

\section{Effects of Environment Temperature and Feeding Restrictions Programs on Performance and Fat Carcass Composition of Broilers}

\begin{abstract}
The objective of this experiment was to study the effects of environmental temperature and feeding restriction programs on performance, carcass and noble cuttings yields and fat, water and protein contents of the carcass, and also the liver glycogen content of broiler chickens under different environmental conditions. A completely randomized block experimental design, in a $5 \mathrm{x} 2$ (feeding program versus sex) factorial arrangement with two replicates within each environmental and 14 birds per experimental plot, was used. At 42 days of age, the temperature and sex negatively affected the intake and weight gain, but the feeding restriction program did not affect them. Temperature, feeding restriction programs and sex did not affect the carcass and noble cutting yields. The feeding restriction programs and the temperature did not affect the carcass fat, water and protein contents. As for sex, the females presented the highest fat contents in the carcass. The glycogen liver contents were negatively affected by the feeding restriction programs and by the sex, however were not affected by the temperature.
\end{abstract}

Key Words: abdominal fat, broiler chickens, carcass and noble cuttings yields, feeding restriction programs, sex, temperature, total fat

\section{Introdução}

A temperatura ambiente é considerada o fator físico de maior efeito no desempenho de frangos de corte, já que exerce grande influência no consumo de ração e, com isto, afeta diretamente o ganho de peso e a conversão alimentar destes animais. Aves submetidas a temperaturas ambientais fora da zona de termoneutralidade respondem com comportamentos alimentares e atitudes físicas características. Ao elevar a temperatura corporal, em função de aumento na temperatura ambiental, as aves aumentam a freqüência respiratória e reduzem o consumo de ração, na tentativa de manter a temperatura corporal dentro de limites fisiológicos. É sabido que o consumo médio da água geralmente corresponde a duas vezes o consumo alimentar. Entretanto, essa relação aumenta em condições de temperaturas extremamente altas. O consumo alimentar é mais crítico no calor, devido aos níveis mais baixos de ingestão, que reduzem o consumo ideal de nutrientes.

A composição da dieta, a temperatura, o tipo de

\footnotetext{
${ }_{1}^{1}$ Parte da Tese apresentada a UFV, pelo primeiro autor para obtenção do título de Doutor em Zootecnia, financiada pelo CNPq

2 Professor do DZO/UFRPE - Recife, PE.

${ }^{3}$ Professor do DZO/UFV - Viçosa, MG.

${ }^{4}$ Professor do Instituto de Ciências Exatas da UFRRJ.
} 
instalação, a idade e o sexo têm influenciado a quantidade de gordura depositada pelos frangos de corte. Porém, muitos autores relataram que, diminuindo a relação caloria/proteína da dieta, é possível obter menor quantidade de gordura abdominal e total na carcaça de frangos de corte (MOLLISOM et al., 1984; McMURTRY, 1987; e COELHO et al., 1993).

O novo perfil da taxa de crescimento do frango "moderno" resultou na elevação da taxa metabólica no início do ciclo produtivo. Essa alteração metabólica tem sido relatada como a maior responsável pelo acúmulo de gordura na carcaça de frangos de corte (CARTER, 1993). Existem várias funções metabólicas que envolvem o fígado e podem ser aumentadas ou diminuídas de acordo com a dieta ingerida. $\mathrm{O}$ fígado tem a função metabólica extremamente importante de regular a concentração no sangue da maioria dos metabólitos, particularmente glicose e aminoácidos. No caso da glicose, isto é alcançado absorvendo seu excesso e convertendo-o em glicogênio ou gordura. Entre as refeições, os depósitos de glicogênio hepático podem ser mobilizados, permitindo a liberação de glicose para o sangue.

Muitos trabalhos foram desenvolvidos no sentido de avaliar os efeitos da temperatura ambiente e a sua inter-relação com fatores dietéticos que poderiam explicar a variação no comportamento das aves. Assim, este experimento foi conduzido para determinar o efeito dos diferentes programas alimentares, em diferentes condições ambientais, sobre o desempenho produtivo, os rendimentos de carcaças e cortes nobres e os teores de gordura, água e proteína da carcaça e de glicogênio no fígado, em frangos de corte.

\section{Material e Métodos}

O experimento foi conduzido na Seção de Avicultura, do Departamento de Zootecnia (DZO), do Centro de Ciências Agrárias (CCA), da Universidade Federal de Viçosa, utilizando 600 pintos, com um dia de idade, da linhagem Hubbard, sendo metade de cada sexo, vacinados contra as doenças de Marek e Bouba Aviária e distribuídos ao acaso em 40 boxes.

Foram utilizados dois galpões de alvenaria, cobertos com telhas de amianto, lanternim e pé direito de 2,80 m. Em um dos galpões foi utilizado um plástico encerado preto nas laterais e no teto do galpão, onde foram colocados aquecedores, para manter a temperatura próxima de $32^{\circ} \mathrm{C}$. No outro galpão, foram abertas as cortinas e colocados ventiladores, mantendo a temperatura próxima à normal (Tabela 1).

Foram utilizados cinco programas de alimentação, sendo um controle ou testemunha, em que as aves receberam alimentação à vontade, por todo o período experimental, e quatro de restrição alimentar quantitativa, aplicados a partir do oitavo dia. Os programas de restrição consistiram na retirada do alimento por um período de 24 horas, a cada dia de restrição. Os programas de restrição alimentar foram: Trat. 1: ração à vontade do $1 \underline{\mathrm{O}}$ ao $42 \underline{\mathrm{O}}$ dia de idade (sem restrição); Trat. 2: restrição no $8^{\circ}$ e no $10^{\circ}$ dia de idade (dois dias de restrição e ração à vontade após o jejum); Trat. 3: restrição no $8^{\mathrm{o}}$ e $10^{0}$ dia de idade (dois dias de restrição e ração controlada após o jejum, 45 e $55 \mathrm{~g}$ para os machos e 40 e $50 \mathrm{~g}$ para as

Tabela 1 - Médias das temperatura máxima, mínima e média semanais $\left({ }^{\circ} \mathrm{C}\right)$

Table 1 - Means of weekly maximum, minimum and average temperatures $\left({ }^{\circ} \mathrm{C}\right)$

\begin{tabular}{|c|c|c|c|c|c|c|}
\hline \multirow[b]{3}{*}{$\begin{array}{l}\text { Período (dias) } \\
\text { Period (days) }\end{array}$} & \multicolumn{6}{|c|}{$\begin{array}{c}\text { Temperatura }\left({ }^{\circ} \mathrm{C}\right) \\
\text { Temperature } \\
\end{array}$} \\
\hline & \multicolumn{3}{|c|}{$\begin{array}{l}\text { Normal } \\
\text { Normal }\end{array}$} & \multicolumn{3}{|c|}{$\begin{array}{l}\text { Alta } \\
\text { High }\end{array}$} \\
\hline & $\begin{array}{l}\text { Máxima } \\
\text { Maximum }\end{array}$ & $\begin{array}{l}\text { Mínima } \\
\text { Minimum }\end{array}$ & $\begin{array}{l}\text { Média } \\
\text { Average }\end{array}$ & $\begin{array}{l}\text { Máxima } \\
\text { Maximum }\end{array}$ & $\begin{array}{l}\text { Mínima } \\
\text { Minimum }\end{array}$ & $\begin{array}{c}\text { Média } \\
\text { Mean }\end{array}$ \\
\hline 01 a 07 & 33,7 & 21,0 & 27,4 & 37,4 & 26,8 & 32,1 \\
\hline 08 a 14 & 32,6 & 20,2 & 26,4 & 37,6 & 26,7 & 32,1 \\
\hline 15 a 21 & 31,8 & 20,1 & 25,9 & 37,4 & 26,9 & 32,1 \\
\hline 22 a 28 & 30,4 & 20,1 & 25,3 & 35,9 & 26,1 & 31,0 \\
\hline 29 a 35 & 27,1 & 18,7 & 22,9 & 34,8 & 24,8 & 29,7 \\
\hline 36 a 42 & 25,6 & 20,1 & 22,8 & 33,4 & 24,2 & 28,8 \\
\hline 1 a 21 & 32,7 & 20,4 & 26,6 & 37,4 & 26,8 & 32,1 \\
\hline 22 a 42 & 27,7 & 19,7 & 23,7 & 34,6 & 25,1 & 29,8 \\
\hline $1 \mathrm{a} 42$ & 30,2 & 20,1 & 25,1 & 36,0 & 25,9 & 31,0 \\
\hline
\end{tabular}


fêmeas, respectivamente, no $9 \mathrm{o}$ e no $11^{\mathrm{o}} \mathrm{dia}$ ); Trat. 4: restrição no $8^{\circ}$, $10^{\circ}, 12^{\circ}$ e e $14^{\circ}$ dia de idade (quatro dias de restrição e ração à vontade após o jejum); e Trat. 5: restrição nos $8^{\circ}$, $10^{\circ}$ o, $12^{\circ}$ e $14^{\circ}$ dia de idade (quatro dias de restrição e ração controlada após o jejum 45, 55, 65 e $75 \mathrm{~g}$ para os machos e 40, 50, 60 e $70 \mathrm{~g}$, para as fêmeas, respectivamente, no 9을, $11^{\circ}, 13^{\circ}$ e no $15^{\circ}$ dia de idade).

Em todos os tratamentos as aves receberam dietas formuladas de acordo com as exigências preconizadas por ROSTAGNO et al. (1983), com dois tipos de ração (inicial, de 1 a 21 dias e crescimento, de 22 a 42 dias de idade). Na semana que antecedeu ao abate, as aves receberam a ração tipo final, que foi a mesma da ração de crescimento, substituindo, porém, o agente anticoccidiano por material inerte. Na Tabela 2, são encontradas as composições centesimais das rações experimentais.

O delineamento experimental foi em blocos casualizados, em um esquema fatorial $5 \times 2$ (cinco programas de restrição alimentar $\mathrm{x}$ dois sexos), com duas repetições dentro de cada ambiente e 14 aves por unidade experimental. As variáveis estudadas foram analisadas estatisticamente utilizando o programa SAEG - Sistema para Análise Estatísticas (UNIVERSIDADE FEDERAL DE VIÇOSA - UFV, 1993). Para as comparações de médias, foi utilizado o teste de Duncan.

Aos 42 dias de idade, foram abatidas duas aves de cada box e retirados os fígados para a determinação dos teores de glicogênio. No abate, as aves foram pesadas, mortas por deslocamento cervical e imediatamente abertas para retirada dos fígados. Em seguida, os fígados foram colocados em sacos plásticos, congelados mediante mergulho em nitrogênio líquido por alguns segundos, com a finalidade de interromper o metabolismo. Posteriormente, os fígados foram pesados e guardados em congelador $\left(-15^{\circ} \mathrm{C}\right)$ para posteriores análises.

Antes do abate, as aves foram submetidas a um jejum de 12 horas e, posteriormente, amostradas aleatoriamente, por tratamento, repetição e bloco (quatro aves por box). Das 160 aves sacrificadas, $50 \%$ foram processadas com a finalidade de realizar os cortes nobres (peito, coxa, sobrecoxa) e as outras aves destinadas ao processo de moagem total da carcaça, para cálculo dos teores corporais de água, gordura e proteína.

O preparo das amostras e as análises de matéria seca, proteína bruta, extrato etéreo e glicogênio foram realizados no Laboratório de Nutrição Animal, do Departamento de Zootecnia, da Universidade Federal de Viçosa, conforme metodologia descrita por SILVA (1990). Para a determinação dos teores de extrato etéreo, as amostras foram submetidas ao processo de pré-desengorduramento, descrito por PRESTON et al. (1974). Os teores de glicogênio foram determinados por método colorimétrico, utilizando os reagentes de Teles (TELES, 1977), tendo como padrão uma solução de glicose.

Tabela 2 - Composição das rações experimentais (\%) Table 2 - Composition of the experimental diets

\begin{tabular}{|c|c|c|c|}
\hline $\begin{array}{l}\text { Ingrediente } \\
\text { Ingredient }\end{array}$ & $\begin{array}{r}\text { Inicial } \\
\text { Initial } \\
\end{array}$ & $\begin{array}{c}\text { Crescimento } \\
\text { Growing }\end{array}$ & $\begin{array}{l}\text { Final } \\
\text { Final } \\
\end{array}$ \\
\hline $\begin{array}{l}\text { Milho } \\
\text { Corn }\end{array}$ & 55,60 & 61,85 & 61,85 \\
\hline $\begin{array}{l}\text { Farelo de soja } \\
\text { Soybean meal }\end{array}$ & 38,05 & 31,90 & 31,90 \\
\hline $\begin{array}{l}\text { Óleo de soja } \\
\text { Soybean oil }\end{array}$ & 2,65 & 2,95 & 2,95 \\
\hline $\begin{array}{l}\text { Fosfato bicálcico } \\
\text { Dicalcium phosphate }\end{array}$ & 1,90 & 1,65 & 1,65 \\
\hline $\begin{array}{l}\text { Calcário } \\
\text { Limestone }\end{array}$ & 1,00 & 0,90 & 0,90 \\
\hline $\begin{array}{l}\text { Suplemento vitamínico } \\
\text { Vitamin supplement }\end{array}$ & 0,10 & 0,10 & 0,10 \\
\hline $\begin{array}{l}\text { Sal iodado } \\
\text { Salt }\end{array}$ & 0,40 & 0,40 & 0,40 \\
\hline $\begin{array}{l}\text { Suplemento mineral } \\
\text { Mineral supplement }\end{array}$ & 0,05 & 0,05 & 0,05 \\
\hline $\begin{array}{l}\text { DL-Metionina }(99 \%) \\
\text { DL-Methionine (99\%) }\end{array}$ & 0,15 & 0,10 & 0,10 \\
\hline $\begin{array}{l}\text { Agente anticoccidiano } \\
\text { Coccidiostat }\end{array}$ & 0,10 & 0,10 & - \\
\hline $\begin{array}{l}\text { Areia lavada } \\
\text { Washed sand }\end{array}$ & - & - & 0,100 \\
\hline & & $\begin{array}{l}\text { Composição } \\
\text { Composition }\end{array}$ & \\
\hline $\begin{array}{l}\mathrm{EM}(\mathrm{kcal} / \mathrm{kg}) \\
M E\end{array}$ & 3000 & 3100 & 3100 \\
\hline $\begin{array}{l}\text { Proteína }(\%) \\
\text { Protein }\end{array}$ & 22,12 & 19,64 & 19,60 \\
\hline $\begin{array}{l}\text { Metionina }(\%) \\
\text { Methionine }\end{array}$ & 0,49 & 0,41 & 0,41 \\
\hline $\begin{array}{l}\text { Metionina + Cistina }(\%) \\
\text { Methionine }+ \text { Cystine }\end{array}$ & 0,85 & 0,74 & 0,74 \\
\hline $\begin{array}{l}\text { Lisina }(\%) \\
\text { Lysine }\end{array}$ & 1,22 & 1,06 & 1,06 \\
\hline $\mathrm{Ca}(\%)$ & 1,06 & 0,92 & 0,92 \\
\hline $\begin{array}{l}\text { P disponível (\%) } \\
\text { Available P }\end{array}$ & 0,45 & 0,40 & 0,40 \\
\hline
\end{tabular}

Available $P$

$1 \mathrm{~kg}$ do produto: Ácido fólico, 1,0 g; Ácido nicotínico (Nicotinic acid), 35,0 g; Bacitracina de zinco (Zinc bacitracin), 10,0 g; Biotina (Biotin), $0,07 \mathrm{~g}$; BHT, 5,0 g; Cloreto de colina (Choline chloride), 100,0 g; Olaquindox (Olaquindox), 5,0 g; Pantotenato de cálcio (Calcium pantotenate), $10,0 \mathrm{~g}$; Se, $0,120 \mathrm{~g}$; Vit. A, $12.000 .000 \mathrm{UI}$; Vit. B $\mathrm{B}_{1}$, 2,0 g; Vit. $B_{6}, 3,0$ g; Vit. $B_{12}, 15.000$ mcg; Vit. $D_{3}, 2.500 .000$ Ul; Vit. E, 30.000 Ul; Vit. $\mathrm{K}_{3}, 3,0 \mathrm{~g}$;

2 kg do produto: Co, 2,0 g; Cu, 20,0 g; Fe, 100,0 g; I, 2,0 g; Mn, $160,0 \mathrm{~g} ; \mathrm{Zn}, 100,0 \mathrm{~g}$. 


\section{Resultados e Discussão}

Os resultados de peso corporal, consumo de ração e conversão alimentar dos frangos de corte aos 42 dias de idade, em relação à temperatura, aos programas de restrição alimentar e sexos estão apresentados na Tabela 3. As interações entre a temperatura, o programa alimentar e o sexo não foram significativas $(P>0,05)$. A temperatura influenciou significativamente $(\mathrm{P}<0,05)$ o consumo alimentar e o peso corporal dos frangos, porém não afetou a conversão alimentar. O peso dos frangos criados no ambiente com temperatura elevadas foi $15 \%$ inferior ao do grupo controle. O consumo de ração decresceu na mesma proporção (15\%), o que fez a conversão alimentar não diferir entre os dois tratamentos. Resultados semelhantes foram encontrados por PERRAULT e LEESON (1992), que verificaram efeito significativo $(\mathrm{P}<0,05)$ da temperatura sobre o peso corporal e o consumo de ração em frangos de corte.

No caso de temperaturas mais altas, as aves consomem menor quantidade da ração e, portanto, têm o ganho de peso reduzido em função do menor consumo. Em temperaturas ambientes abaixo de $29^{\circ} \mathrm{C}$, não são observados efeitos consistentes sobre a temperatura corporal, a qual, entretanto, aumenta consideravelmente quando a temperatura ambiente atinge $32^{\circ} \mathrm{C}$. Quando a temperatura ambiente é menor ou igual a $35^{\circ} \mathrm{C}$ e a umidade relativa do ar, inferior a $55 \%$, os efeitos sobre a temperatura corporal são pouco significativos. Assim, é mais importante adotar baixa umidade relativa, quando a temperatura do ambiente é alta. Apesar de ser esperado que a eficiência alimentar diminuísse com a elevação da temperatura ambiental, os dados obtidos demonstraram que isso só ocorre nos casos em que temperatura e umidade são elevadas.

O programa de restrição alimentar influenciou $(\mathrm{P}<0,05)$ o consumo de ração e o peso corporal, mas não $(\mathrm{P}>0,05)$ a conversão alimentar dos frangos de corte aos 42 dias de idade. Resultados semelhantes foram observados por CERNIGLIA et al. (1983), FARREL e SWAIN (1987) e PERRALT e LEESON (1992), que verificaram ganhos de pesos significativamente reduzidos, quando compararam grupos de aves com alimentação à vontade e restrita, em altas temperaturas.

Quanto ao sexo, foram observadas diferenças significativas $(\mathrm{P}<0,05)$ para consumo de ração, peso corporal e conversão alimentar. Os machos foram, em média, $15 \%$ mais pesados que as fêmeas, porém consumiram mais ração.

Na Tabela 4, encontram-se os pesos ao abate de carcaça, peito, coxa, sobrecoxa e fígados dos frangos de corte abatidos aos 42 dias de idade.

Tabela 3 - Consumo de ração (g), peso médio (g) e conversão alimentar dos frangos de corte, aos 42 dias de idade, de acordo com o programa alimentar, o sexo e a temperatura

Table 3 - Feed intake $(g)$, average weight $(g)$ and feed:gain ratio $(g)$ of broiler chickens at 42 days of age, according to the feeding program, sex and temperature

\begin{tabular}{lccc}
\hline $\begin{array}{l}\text { Programa alimentar } \\
\text { Feeding } \text { program }^{1}\end{array}$ & $\begin{array}{c}\text { Consumo de ração } \\
\text { Feed intake }\end{array}$ & $\begin{array}{c}\text { Peso corporal } \\
\text { Bodyweight }\end{array}$ & $\begin{array}{c}\text { Conversão alimentar } \\
\text { Feed:gain ratio }\end{array}$ \\
\hline 1 & $4507^{\mathrm{a}}$ & $2123^{\mathrm{a}}$ & $2,16^{\mathrm{a}}$ \\
2 & $4476^{\mathrm{a}}$ & $2097^{\mathrm{a}}$ & $2,12^{\mathrm{a}}$ \\
3 & $4275^{\mathrm{b}}$ & $2068^{\mathrm{a}}$ & $2,11^{\mathrm{a}}$ \\
5 & $4146^{\mathrm{c}}$ & $2048^{\mathrm{a}}$ & $2,07^{\mathrm{a}}$ \\
5 & $4040^{\mathrm{c}}$ & $1954^{\mathrm{b}}$ & $2,11^{\mathrm{a}}$ \\
Macho $^{2}$ & $4409^{\mathrm{a}}$ & $2213^{\mathrm{a}}$ & $2,07^{\mathrm{a}}$ \\
Male $^{2}$ & $4028^{\mathrm{b}}$ & $1901^{\mathrm{b}}$ & $2,16^{\mathrm{b}}$ \\
Fêmea $^{2}$ & & & $2,12^{\mathrm{a}}$ \\
Female $^{2}$ & $4599^{\mathrm{a}}$ & $2214^{\mathrm{a}}$ & $2,13^{\mathrm{a}}$ \\
Temperatura normal $^{2}$ & $3959^{\mathrm{b}}$ & $1900^{\mathrm{b}}$ & 3,42 \\
$\begin{array}{l}\text { Normal temperature } \\
\text { Temperatura alta }\end{array}$ & & & 5,4 \\
$\begin{array}{l}\text { High temperature } \\
\text { CV }(\%)\end{array}$ & 5,4 & & \\
\hline
\end{tabular}

${ }_{1}^{1}$ Médias na mesma variável, seguidas de letras diferentes na coluna, diferem $(P<0,05)$ pelo teste Duncan.

2 Significativo $(P<0,05)$ pelo teste $F$.

1 Means in the same variable, followed by different letters, within a column, differ $(P<.05)$ by Duncan test.

2 Significant $(P<.05)$ by $F$ test. 
Rev. bras. zootec.

Tabela 4 - Peso ao abate e pesos de carcaça, peito, coxa e sobrecoxa em frangos de corte, aos 42 dias de idade, de acordo com o programa alimentar, o sexo e a temperatura

Table 4 - Slaughter weight $(\mathrm{g})$ and weights of carcass, breast, thigh and drumstick of broiler chickens at 42 days of age, according to the feeding program, sex and temperature

\begin{tabular}{|c|c|c|c|c|c|c|}
\hline $\begin{array}{l}\text { Programa alimentar } \\
\text { Feeding program }^{1}\end{array}$ & $\begin{array}{l}\text { Peso ao } \\
\text { abate }(\mathrm{g}) \\
\text { Weight at } \\
\text { slaughter }\end{array}$ & $\begin{array}{c}\text { Peso de } \\
\text { carcaça }(\mathrm{g}) \\
\text { Carcass } \\
\text { weight } \\
\end{array}$ & $\begin{array}{l}\text { Peso de } \\
\text { peito }(\mathrm{g}) \\
\text { Breast } \\
\text { weight }\end{array}$ & $\begin{array}{l}\text { Peso de } \\
\text { coxa }(\mathrm{g}) \\
\text { Thigh } \\
\text { weight } \\
\end{array}$ & $\begin{array}{c}\text { Peso de } \\
\text { sobrecoxa (g) } \\
\text { Drumstick } \\
\text { weight } \\
\end{array}$ & $\begin{array}{c}\text { Peso de } \\
\text { fígado (g) } \\
\text { Liver } \\
\text { weight } \\
\end{array}$ \\
\hline $\begin{array}{l}1 \\
2 \\
3 \\
4 \\
5\end{array}$ & $\begin{array}{l}2064^{\mathrm{a}} \\
198^{\mathrm{a}} \\
1891^{\mathrm{b}} \\
1890^{\mathrm{b}} \\
1890^{\mathrm{b}}\end{array}$ & $\begin{array}{l}1845^{\mathrm{a}} \\
1767^{\mathrm{a}} \\
1730^{\mathrm{b}} \\
1703^{\mathrm{b}} \\
1709^{\mathrm{b}}\end{array}$ & $\begin{array}{l}395,7^{\mathrm{a}} \\
382,8^{\mathrm{a}} \\
373,6^{\mathrm{a}} \\
369,6^{\mathrm{a}} \\
373,8^{\mathrm{a}}\end{array}$ & $\begin{array}{c}219,9^{\mathrm{a}} \\
215,8^{\mathrm{a}} \\
202,4^{\mathrm{bc}} \\
201,4^{\mathrm{bc}} \\
198,4^{\mathrm{c}}\end{array}$ & $\begin{array}{c}222,8^{\mathrm{a}} \\
213,0^{\mathrm{ab}} \\
202,1^{\mathrm{bc}} \\
210,3^{\mathrm{ab}} \\
196,1^{\mathrm{c}}\end{array}$ & $\begin{array}{c}52,7^{\mathrm{a}} \\
51,4^{\mathrm{a}} \\
47,9^{\mathrm{a}} \\
47,4^{\mathrm{a}} \\
46,11^{\mathrm{b}}\end{array}$ \\
\hline $\begin{array}{l}\text { Macho }^{2} \\
\text { Male }^{2} \\
\text { Fêmea }^{2} \\
\text { Female }^{2}\end{array}$ & $\begin{array}{l}2123^{\mathrm{a}} \\
1763^{\mathrm{b}}\end{array}$ & $\begin{array}{l}1909^{\mathrm{a}} \\
1590^{\mathrm{b}}\end{array}$ & $\begin{array}{l}412,7^{\mathrm{a}} \\
345,5^{\mathrm{b}}\end{array}$ & $\begin{array}{l}233,3^{\mathrm{a}} \\
181,5^{\mathrm{b}}\end{array}$ & $\begin{array}{l}231,2^{\mathrm{a}} \\
186,4^{\mathrm{b}}\end{array}$ & $\begin{array}{l}52,5^{\mathrm{a}} \\
46,5^{\mathrm{b}}\end{array}$ \\
\hline $\begin{array}{l}\text { Temperatura normal }^{2} \\
\text { Normal temperature }^{2} \\
\text { Temperatura alta }^{2} \\
\text { High temperature }^{2}\end{array}$ & $2097^{a}$ & $1613^{b}$ & $\begin{array}{l}411,8^{\mathrm{a}} \\
346,4^{\mathrm{b}}\end{array}$ & $\begin{array}{l}219,2^{\mathrm{a}} \\
195,6^{\mathrm{b}}\end{array}$ & $\begin{array}{l}223,7^{\mathrm{a}} \\
193,9^{\mathrm{b}}\end{array}$ & $\begin{array}{l}50,6^{\mathrm{a}} \\
48,4^{\mathrm{b}}\end{array}$ \\
\hline $\mathrm{CV}(\%)$ & 4,4 & 5,2 & 7,7 & 6,4 & 7,3 & 6,1 \\
\hline
\end{tabular}

1 Médias na mesma variável, seguidas de letras diferentes na coluna, diferem $(P<0,05)$ pelo teste Duncan.

2 Significativo $(\mathrm{P}<0,05)$ pelo teste $\mathrm{F}$.

1 Means in the same variable, followed by different letters, within a column, differ $(P<.05)$ by Duncan test.

2 Significant $(P<.05)$ by $F$ test.

A temperatura, o programa alimentar e o sexo influenciaram significativamente $(\mathrm{P}<0,05)$ os pesos ao abate, carcaça, peito, coxa e sobrecoxa dos frangos de corte e as interações não foram significativas. Os pesos de carcaça, peito, coxa e sobrecoxa foram, em média, $14 \%$ menor para as aves criadas em altas temperaturas. Resultados semelhantes foram observados por KUBENA et al. (1972), que verificaram diferenças significativas $(\mathrm{P}<0,05)$ nos pesos de carcaça, peito, coxa e sobrecoxa em frangos de corte abatidos aos 42 dias de idade, quando criados em ambiente com altas temperaturas. Porém, são discordantes daqueles obtidos por PERRAULT e LEESON (1992), que não encontraram diferenças significativas sobre os pesos de peito, coxa e sobrecoxa em frangos de corte, aos 42 dias de idade, quando variaram a temperatura ambiente.

$\mathrm{Na}$ Tabela 5, encontram-se os rendimentos ao abate de carcaça, peito, coxa e sobrecoxa em relação à temperatura, os programas alimentares e o sexo de frangos de corte, aos 42 dias de idade. Foi observado efeito significativo $(\mathrm{P}<0,05)$ da temperatura apenas para o rendimento ao abate e rendimento de coxa. Para os programas alimentares, não foram verificadas diferenças significativas $(\mathrm{P}>0,05)$ para qualquer das variáveis. Quanto ao sexo, foi observada diferença significativa $(\mathrm{P}<0,05)$ somente para rendimento de coxa. As interações entre temperatura, programa alimentar e sexo não foram significativas. Resultados semelhantes foram encontrados por PERRAULT e LEESON (1992), que, trabalhando com frangos de corte, não encontraram diferenças significativas $(\mathrm{P}<0,05)$ para o rendimento de peito em frangos de corte, aos 42 dias de idade, quando variaram a temperatura ambiente e o regime alimentar.

Os resultados dos teores de extrato etéreo, água e proteína na carcaça e glicogênio dos fígados de frangos de corte, em relação à temperatura, ao programa de restrição alimentar e a sexo, abatidos aos 42 dias de idade, encontram-se na Tabela 6. As interações entre temperatura, programa alimentar e sexo não foram significativas.

As temperaturas ambiente e os programas alimentares não influenciaram os teores de extrato etéreo, água e proteína da carcaça das aves. Em média, foram observados $15 \%$ de extrato etéreo corporal nas carcaças e $63 \%$ de água, enquanto a proteína foi em torno de $18 \%$. O sexo influenciou $(\mathrm{P}<0,05)$ os teores de extrato etéreo e de água das carcaças dos frangos. No entanto, SWAIN e FARREL (1975) verificaram aumento nos teores de gordura corporal na carcaça de frangos de corte, 
LANA et al.

Tabela 5 - Rendimentos (\%) ao abate, de carcaça, peito, coxa e sobrecoxa em frangos de corte, aos 42 dias de idade, de acordo com o programa alimentar, o sexo e a temperatura

Table 5 - Yields (\%) at slaughter, of carcass, breast, thigh and drumstick of broiler chickens at 42 days of age, according to the feeding program, sex and temperature

\begin{tabular}{lccccc}
\hline $\begin{array}{l}\text { Programa alimentar } \\
\text { Feeding program }^{1}\end{array}$ & $\begin{array}{c}\text { Rendimento } \\
\text { ao abate } \\
\text { Slaughter yield }\end{array}$ & $\begin{array}{c}\text { Rendimento } \\
\text { de carcaça } \\
\text { Carcass yield }\end{array}$ & $\begin{array}{c}\text { Rendimento } \\
\text { de peito } \\
\text { Breast yield }\end{array}$ & $\begin{array}{c}\text { Rendimento } \\
\text { de coxa } \\
\text { Thigh yield }\end{array}$ & $\begin{array}{c}\text { Rendimento } \\
\text { de sobre coxa } \\
\text { Drumstick yield }\end{array}$ \\
\hline 1 & $95,44^{\mathrm{a}}$ & $89,53^{\mathrm{a}}$ & $21,40^{\mathrm{a}}$ & $11,87^{\mathrm{a}}$ & $12,07^{\mathrm{a}}$ \\
2 & $95,66^{\mathrm{a}}$ & $89,54^{\mathrm{a}}$ & $21,68^{\mathrm{a}}$ & $12,19^{\mathrm{a}}$ & $12,04^{\mathrm{a}}$ \\
3 & $95,93^{\mathrm{a}}$ & $91,50^{\mathrm{a}}$ & $21,60^{\mathrm{a}}$ & $11,68^{\mathrm{a}}$ & $11,66^{\mathrm{a}}$ \\
4 & $95,17^{\mathrm{a}}$ & $89,92^{\mathrm{a}}$ & $21,70^{\mathrm{a}}$ & $11,82^{\mathrm{a}}$ & $12,30^{\mathrm{a}}$ \\
5 & $95,79^{\mathrm{a}}$ & $90,03^{\mathrm{a}}$ & $21,98^{\mathrm{a}}$ & $11,63^{\mathrm{a}}$ & $11,51^{\mathrm{a}}$ \\
\hline Macho $^{2}$ & $95,65^{\mathrm{a}}$ & $89,97^{\mathrm{a}}$ & $21,61^{\mathrm{a}}$ & $12,24^{\mathrm{a}}$ & $12,09^{\mathrm{a}}$ \\
Male $^{2}$ & $95,15^{\mathrm{a}}$ & $90,14^{\mathrm{a}}$ & $21,74^{\mathrm{a}}$ & $11,45^{\mathrm{b}}$ & $11,75^{\mathrm{a}}$ \\
Fêmea $^{2}$ & & & & & \\
Female $^{2}$ & $94,63^{\mathrm{a}}$ & $89,97^{\mathrm{a}}$ & $21,87^{\mathrm{a}}$ & $11,58^{\mathrm{a}}$ & $11,83^{\mathrm{a}}$ \\
Temperatura normal $^{2}$ & & & & & \\
Normal temperature $^{2}$ & $96,18^{\mathrm{b}}$ & $90,13^{\mathrm{a}}$ & $21,48^{\mathrm{a}}$ & $12,10^{\mathrm{b}}$ & $12,00^{\mathrm{a}}$ \\
Temperatura alta $^{2}$ & & & & & \\
High temperature $^{2}$ & 1,1 & 2,2 & 3,6 & 4,8 & 4,8 \\
\hline CV $(\%)$ & & &
\end{tabular}

1 Médias na mesma variável, seguidas de letras diferentes na coluna, diferem $(P<0,05)$ pelo teste Duncan.

2 Significativo $(P<0,05)$ pelo teste $F$.

1 Means in the same variable, followed by different letters, within a column, differ $(P<.05)$ by Duncan test.

2 Significant $(P<.05)$ by $F$ test.

Tabela 6 - Teores (\%) de água, extrato etéreo, proteína da carcaça e glicogênio do fígado de frangos de corte, aos 42 dias de idade, de acordo com o programa alimentar, o sexo e a temperatura

Table 6 - Contents (\%) of water, ether extract, carcass protein and liver glycogen of broiler chickens at 42 days of age, according to the feeding program, sex and temperature

\begin{tabular}{lcccc}
\hline Programa alimentar $^{1}$ & $\begin{array}{c}\text { Água } \\
\text { Weeding program }\end{array}$ & $\begin{array}{c}\text { Extrato etéreo } \\
\text { Etherextract }\end{array}$ & $\begin{array}{c}\text { Proteína } \\
\text { Protein }\end{array}$ & $\begin{array}{c}\text { Glicogênio } \\
\text { Glycogen }\end{array}$ \\
\hline 1 & $63,51^{\mathrm{a}}$ & $15,50^{\mathrm{a}}$ & $18,38^{\mathrm{a}}$ & $9,20^{\mathrm{a}}$ \\
2 & $63,04^{\mathrm{a}}$ & $15,66^{\mathrm{a}}$ & $18,37^{\mathrm{a}}$ & $7,73^{\mathrm{b}}$ \\
3 & $64,16^{\mathrm{a}}$ & $14,32^{\mathrm{a}}$ & $17,89^{\mathrm{a}}$ & $7,12^{\mathrm{b}}$ \\
4 & $63,40^{\mathrm{a}}$ & $15,33^{\mathrm{a}}$ & $18,01^{\mathrm{a}}$ & $7,10^{\mathrm{b}}$ \\
5 & $63,00^{\mathrm{a}}$ & $15,69^{\mathrm{a}}$ & $18,16^{\mathrm{a}}$ & $7,08^{\mathrm{b}}$ \\
\hline Macho $^{2}$ & $63,82^{\mathrm{a}}$ & $14,60^{\mathrm{a}}$ & $18,76^{\mathrm{a}}$ & $7,34^{\mathrm{a}}$ \\
Male $^{2}$ & $62,95^{\mathrm{b}}$ & $15,96^{\mathrm{b}}$ & $18,16^{\mathrm{a}}$ & $8,95^{\mathrm{b}}$ \\
Fêmea $^{2}$ & & & & \\
Female $^{2}$ & $63,18^{\mathrm{a}}$ & $15,41^{\mathrm{a}}$ & $18,95^{\mathrm{a}}$ & $8,24^{\mathrm{a}}$ \\
Temperatura normal $^{2}$ & & & $18,50^{\mathrm{a}}$ & $8,05^{\mathrm{a}}$ \\
Normal temperature $^{2}$ & $63,58^{\mathrm{a}}$ & $15,15^{\mathrm{a}}$ & & \\
Temperatura alta $^{2}$ & & & 3,40 & 10,09 \\
High temperature $^{2}$ & 1,68 & 8,69 &
\end{tabular}

${ }_{1}^{1}$ Médias na mesma variável, seguidas de letras diferentes na coluna, diferem $(P<0,05)$ pelo teste Duncan.

2 Significativo $(P<0,05)$ pelo teste $F$.

1 Means in the same variable, followed by different letters, within a column, differ $(P<.05)$ by Duncan test.

2 Significant $(P<.05)$ by $F$ test. 
quando submetidos a temperaturas mais altas.

Os teores de glicogênio diminuíram com o aumento da intensidade de restrição alimentar e, conseqüentemente, quando o nível de glicogênio decresce no fígado, diminui a deposição de gordura na carcaça. As fêmeas apresentaram valores mais elevados de glicogênio que os machos $(\mathrm{P}>0,05)$ e a temperatura não influiu nos teores de glicogênio. ROSTAGNO e FEATHERSTON (1970) verificaram alterações hormonais e enzimáticas em frangos de corte quando alimentados com diferentes dietas. Também demonstraram que o jejum por um período de 48 horas resulta em diminuição dos teores de glicogênio no fígado em frangos de corte e, após a realimentação, os níveis hormonais e enzimáticos retornaram ao normal, não diferindo do grupo controle, alimentado à vontade. Machos apresentaram valores mais elevados de glicogênio hepático que as fêmeas $(\mathrm{P}<0,05)$ e as temperaturas não influenciaram $(\mathrm{P}<0,05)$ os teores de glicogênio hepático.

\section{Conclusões}

A temperatura ambiente e a restrição alimentar influenciaram negativamente o desempenho produtivo dos frangos, no entanto, não houve influência sobre a conversão alimentar.

Os teores de glicogênio diminuíram com o aumento da intensidade da restrição alimentar, reduzindo a deposição de gordura na carcaça. As fêmeas apresentaram maiores teores de glicogênio no fígado e, conseqüentemente, depositaram mais gordura na carcaça.

\section{Referências Bibliográficas}

CARTER, I. Evolução genética dos frangos de corte até o século XXI. In: CONGRESSO BRASILEIRO DE AVICULTURA, 1993, Brasília. Anais... Brasília: CBA, 1993. p.34-37.

CERNIGLIA, G.J., HERBERT, J.A., WATTS, A.B. 1983. The effect of constant ambient temperature and ration on the performance of sexed broilers. Poult. Sci., 62(5):746-754.

COELLO, C.L. 1993. El síndrome ascítico en pollos de engorda. In: CONFERÊNCIA APINCO DE CIÊNCIA E TECNOLOGIA AVÍCOLAS, Santos. Anais... Santos: FACTA, p.221-248.

FARRELL, D.J., SWAIN, S. 1987. Effects of temperatures treatments on the energy and nitrogen metabolism of fed chickens. Br. Poult. Sci., 18(5):735-748.

KUBENA, L.F., LOTT, B.D., DEATON, J.W. et al. 1972. Body composition of chicks as influenced by environmental temperature and selected dietary factors. Poult. Sci. 51(2):517-522.

MAY, J.D. 1987. Bode temperature of aclimated broilers furing exposure to high temperature. Poult. Sci., 66(2):378-380.
McMURTRY, J. 1987. Early restriction decreases body fat. Broilers Industry, 56(1):2-15.

MOLLISON, B., GUENTER, W., BOYCOTT, B.R. 1984. Abdominal fat deposition and sudden death syndrome in broilers: the effects of restricted intake, early life calorie (fat) restriction, and calorie: protein ratio. Poult. Sci., 63(6): 1190-2000.

PERRAULT, N., LEESON, S. 1992. Effect of environmental temperature, dietary energy, and feeding level on growth carcass composition of male broiler chickens to 35 days of age. Can. J. Anim. Sci., 72(4):695-702.

PRESTON, R.L., VANCE, R.D., CAHIL, V.R. 1974. et al. Carcass specific gravity and carcass composition in cattle and the effect of bone proportionality on this relationship. J. Anim. Sci., 38(1):47-51.

REECE, F.N., McNAUGHTON, J.L.1985. Effects of dietary nutrient density on broiler performance at low and moderate environmental temperatures. Poult. Sci., 61(11):2208-2211.

ROSTAGNO, H.S., FEATHERSTON, W.R. 1970. Influence of protein intake, fasting and refeeding on lives size and composition in chicks. Poult. Sci., 49(6):1719-1727.

ROSTAGNO, H.S., SILVA, D.J., COSTA, P.M.A. et al. 1983. Composição de alimentos e exigências nutricionais de aves e suínos (tabelas brasileiras). Viçosa, MG: UFV, Impr. Univ. 59p.

SILVA, D.J. 1990. Análise de alimentos: (métodos químicos e biológicos). Viçosa, MG: UFV, Impr. Univ. 165p.

SWAIN, S., FARRELL, D.J. 1975. Effects of different temperature regimens on body composition and carry-over effects on energy metabolism of growing chickens. Poult. Sci., 54(2):513-520.

TELES, F.F.F. The nutrient analysis of prickey plar. Arizona, USA: University of Arizona, 1977. 157p. Thesis (Doctor in Chemistry) - University of Arizona, 1977.

UNIVERSIDADE FEDERAL DE VIÇOSA - UFV. 1993. Manual de utilização do programa SAEG - Sistema para análises estatística e genéticas. Viçosa, MG: UFV. 59p.

Recebido em: 21/05/1997

Aceito em: 21/12/1999 